\title{
ONLINE COMPONENT CHALLENGES OF A BLENDED LEARNING EXPERIENCE: A COMPREHENSIVE APPROACH
}

Dr. Manal BAYYAT

ORCID: 0000-0002-0151-5810

School of Sport Science

University of Jordan

Amman, JORDAN

Zainab ABU MUAILI

ORCID 0000-0002-4765-842X

School of Sport Science

University of Jordan

Amman, JORDAN

Lujayn ALDABBAS

ORCID: 0000-0003-3161-8957

Princess Sumaya University for Technology (PSUT)

Amman, JORDAN

Received: 22/10/2020 Accepted: 15/02/2021

\begin{abstract}
This study aims to investigate: (1) the construct validity of the "Blended Learners' Online Component Challenges" BLOCC scale. (2) the internal reliability of the scale, and (3) the differences between blended learners' online component challenges according to different socio-demographic variables for Sport Science students. The sample of the study consisted of 263 students enrolled in blended learning classes at the School of Sport Sciences/ University of Jordan. The BLOCC scale was used to collect the required data. The scale measures the four different online component challenges; (1) Self-Management Challenges (SMC), (2) Technology Competency and Literacy Challenges (TCLC), (3) Student Isolation Challenges (SIC), and (4) Technological Sufficiency and Complexity Challenges (TSCC). BLOCC scale proved to be valid and reliable (four items were omitted); The overall fit statistics for the hypothesized four factor model $(\chi 2(\mathrm{df}=2.69)=603.47, \mathrm{p}<0.001$, (RMSEA) $=.08$ indicated a moderate and acceptable fit to the data representing the latent factor structure. Discriminant validity ranged between .53 and .70., Item-to-total correlation (.55 and .72), Cronbach Alpha (.72 and .86), and composite reliability $(.74-.95)$. Results of the study revealed that male students, students who have no internet accessibility, and those who have no previous experience in blended learning classes, all encountered significant higher levels of all BLOCC subscales. Older students (26-30 years old), and those with the lowest total income/ month ( $<500 \mathrm{JD})$ encountered significant levels of TLCC and TSCC. Students with lower literacy in computer skills level encountered significant differences in SMC, TLCC and TSCC. We encourage future studies to propose and implement curative approaches to face such online component challenges.
\end{abstract}

Keywords: Blended learning, higher education, scale validation, online component challenges.

\section{INTRODUCTION}

At the beginning of 2000, Blended Learning (BL) became a popular pedagogical concept (Guzer, \& Caner, 2014). It meets the needs of different learners, learning goals, and learning environments, (Stubbs et al., 2006). The social constructivist approach is used to transform teaching traditional modules into the BL approach, moreover, support educational differentiation, reduce lecturing time, and support repetition (Dalsgaard \& Godsk, 2007). 
BL is considered as an important pedagogical design. It is defined as an effective combination of online and Face to Face (FTF) education, careful planning of the online component needs to take into consideration the capacity of the institutions, the subject matter, and student's needs to optimize the use of active learning strategies (Dos, 2014). BL exposes students to an authentic learning experience with flexible active learning and greater feedback (Bonk et al., 2002).

Potentially BL can improve the learning and satisfaction of both students and instructors at a reasonable cost (Bourne et al., 2005; Pizzi, 2014). Undergraduate course students revealed overall satisfaction and positive perception towards implementing the BL model. They were satisfied with online quizzes and interactive content. Moreover, student-led activities and student-centered practices, particularly collaborative projects, were key themes for effective instructional strategies (Dos, 2014; Tamim, 2018). Students engaged in BL courses reported high levels of interaction with their teachers (Napier et al., 2011).

Information and communication technologies are identified as providers of learning advantages, along with traditional methods such as lectures. Since the beginning of the 21st century, computer network technology has brought enormous transformation to people's life (Le, 2011; Mitchell \& Forer, 2010). Online material had to be engaging, interactive, and complement the FTF classes (Keogh et al., 2017).

To support learners using a distance learning model, the BL approach delivers learning resources and activities using a virtual learning environment (Hughes, 2007). A Moodle is used to effectively facilitate the BL process. It is an open-source software package and a model of interaction among learners and educators, through which learning experiences and outcomes become more vivid and outstanding (Zhou et al., 2017). Moodle platform helps to configure homework, online forums, and other related activities. Also, it optimizes the communication modes in the teaching process in which seminar, chat, and forum modules provide a variety of exchanging platform for both students and teachers (Feng, 2018). Moreover, BL assists educators to online track and target 'at risk' learners more quickly (Hughes, 2007).

The last few years have registered a remarkable increase in Internet use in education, Also, higher educational institutions continuously invested in integrating the technology components into their course offerings (Bailey \& Morais, 2005). BL is still in its early stages in the University of Jordan but is getting increased attention and recognition from students, teachers, and stakeholders. As it is the case of other Arab countries such as the United Arab Emirates (Tamim, 2018). Although, advocates of a BL course portray an ideal picture of participants enjoying learning and revealing how they can employ their new experiences. The truth is, of course, much more complicated, especially for working adults (Tay, 2016).

\section{Purpose of the Study}

School of Sport Sciences at the University of Jordan teach both practical and theoretical classes. Recently, some of these classes started to implement the blended learning approach. In this study we will focus on some of these theoretical blended learning classes such as Sport Psychology, motor learning and Life Skills. We need to address and understand the online component challenges our students face, so we can improve their learning experience and environment. The "Blended Learners' Online Component Challenges" Scale (BLOCC) which was developed and preliminary validated by (Bayyat et al., 2020) will help to shed the light on these challenges, provide further tests on the scale, and to furthermore check that the validity and reliability of the scale. Also, to determine whether the scale can identify differences in BLOCC according to different socio demographic variables.

Statement of the problem: The present study was designed to test and assess the following:

1. The scale's construct validity by investigating whether the scale produces responses measuring the construct "Blended Learners' Online Component Challenges", and whether the four specific online component dimensions identified previously would be found with a diverse sample of students.

2. The internal reliability of the scale by investigating whether the different items seem to be measuring the same dimension in each subscale produces results that are internally consistent.

3. The differences between blended learners' online component challenges (dependent variables) according to different demographic variables (independent variables); (1) gender, (2) internet accessibility, (3) previous experience in BL courses, (4) job status, (5) marital status, (6) student's nationality, (7) province, (8) age, (9) total income per month, (10) literacy in computer skills, and (11) academic year. 


\section{Significance of the Study}

Most previous studies in blended learning focused on planning, managing and evaluating the activities of a blended learning class without considering students' perception of their own learning and experience regarding online component challenges they encounter, In addition to investigating different variables, previously mentioned, that might affect students encountering such challenges.

\section{METHOD}

To fulfil the objectives of this study, the descriptive approach was conducted using the quantitative method and applying the survey design.

\section{Participants}

The initial number of the opportunity sample participated in our study was 272 samples for the 27 items instrument. They were approximately fifty percent of the total number of undergraduate students enrolled in several blended learning classes at the School of Sport Sciences /University of Jordan. Their participation was voluntary. Participants were asked to respond to the "Blended Learners' Online Component Challenges" Scale, they were assured that their responses would be anonymous, and that the results of the study will be used for scientific research only. The study started in November 2019 and was concluded in January 2020.

\section{Data Collection and Analysis}

\section{The Scale}

\section{"Blended Learners" Online Component Challenges" Scale (BLOCC)}

The" Blended Learners' Online Component Challenges" (BLOCC) Scale was adopted to fulfill the purpose of the study, It is a four components scale consisting of twenty seven items. The scale is previously developed and validated, with alpha coefficients values ranging between .72 and .86 for the subscales, and a total of .93 (Bayyat et al., 2020). Compatible with the theoretical review Bower, 2015; Zacharis, 2015; Lightner \& Lightner-Laws, 2016; Safford \& Stinton, 2016; Szeto and Cheng, 2016; Broadbent, 2017; Chyr et al., 2017; Sun et al., 2017; Akcayir \& Akcayir, 2018; AlJarrah et al., 2018; Chuang et al., 2018; Maycock et al., 2018; Prasad et al., 2018; Rasheed et al., 2020), these subscales explain approximately $55 \%$ of the construct's total explained variance.

A five-point Likert type scale was used to rate the answers of the scale's questions; the participants' correspondent would range from 1 point to 5 points (never, occasionally, moderately, usually, and always).

The online component challenges consisted of; self-management challenges (SMC), technological literacy and competency challenges (TLCC), students' isolation challenges (SIC), "technological sufficiency and complexity challenges (TSCC)". Each challenge was identified as single and non-ambiguous explained as follows;

SMC involves a set of six challenges reflected through items 1,2,3,4,5 and 6 in the BLOCC scale. Learners might face different challenges in relation to self-regulating their feelings, thoughts, and behavior to fulfil their learning goals. They include poor time management skills, improper utilization of online peer learning strategies, limited preparation before class, procrastination, online help-seeking challenge and lack of self-management skills,

TLCC involves a set of nine challenges reflected through items 7,8,9,10,11,12,13,14 and 15 in the BLOCC scale. Learners might face different challenges in relation to their competency and proficiency in using technology for studying effectively. They include adult learners' intimidation by learning technologies, the challenge of learning new technology by adult learners, handling different user interfaces, lack of technological competency, students' perception of technology as a barrier to online help-seeking. student technological illiteracy, resistance to/or confusion about seeking appropriate online help, a technological distraction from overly complex technology, poor understanding of expectations and directions in "online learning" of blended learning, and resistance to technology,

SIC involves a set of four challenges reflected through items 16,17,18 and 19 in the BLOCC scale. Learners might face different challenges in relation to emotional distress students feel when they study out of their 
face-to-face classes due to loneliness and isolation from their peers, They include students losing interest in learning and feeling isolated, or do not feel comfortable to be the center of attention during an online session, and students who are not capable of applying the technology related to online classes such as video projection, microphones, and speakers. They include students feeling disinterested and isolated, or feeling uncomfortable being the center of attention during an online class, students isolation and alienation in online learning, students' problems with the use of video projection, the microphones and speakers, and remote.

TSCC involves a set of eight challenges reflected through items 20,21,22,23,24,25,26, and 27 in the BLOCC scale. Learners might face different challenges in relation to access to sufficient online technologies and services for studying or with complex technologies. They include inequality of technological accessibility between students, insufficient access to technology, low bandwidth and slow processing speeds, outdated technology, lack of internet out of the class, experiencing technical difficulties while trying to complete their assignments. technological distraction from overly complex technologies, and challenge with longer videos for learning. The validity and reliability processes in data collection and analyses should be described sufficiently.

\section{Statistical Analysis}

To fulfil our research objectives, we applied the SPSS and AMOS (version 22) software.

Descriptive analysis for demographic information of the sample of the study and for all subscales were calculated, we checked that participants' responses were using the full range of responses (from 1 to 5) throughout the scale. Then, we verified that the distribution of the collected data did not show any evidence of skewness or kurtosis.

Confirmatory factor analysis (CFA) was used to test the BLOCC scale's construct validity, we needed to check that the scale would factor out the four components previously identified in the original study (Bayyat et al., 2020), and that the item loadings are significant.

Reliability of the scale was assessed using different scores of correlations reflecting the Item to total, internal consistency, and composite reliability.

Discriminant validity was checked to emphasize that the subscales of the scale that should not be related are not, or correlate with a minimum degree.

Finally, t-test and one-way ANOVA reflected the ability of the scale to differentiate between different subgroups within the population.

\section{FINDINGS}

We received 272 responses from the undergraduate students enrolled in several blended learning classes at the School of Sport Sciences/University of Jordan; 9 questionnaires (3.3\%) were spoiled and eliminated due to missing data, leaving 263 completed questionnaires for analysis.

Demographic information of the participants were reported as follows; 249 (94.7\%) were Jordanian, 132 (50.2\%) were women and 131 (49.8\%) were men;165 (62.7\%) were aged under 20 years old, $84(31.9 \%)$ were aged 21-25, and 14 (5.3\%) 26-30. 251 (95.4\%) were single and 12 (4.6\%) were married. 92 (35\%) had a job, $133(50 \%)$ were in their first academic year, $69(26 \%)$ in the second year, $21(8 \%)$ in the third year, and $40(15.2 \%)$ in the fourth year. $231(87.8 \%)$ lives in the central territory of Jordan, $28(10.6 \%)$ lives in the northern territory, and only $4(1.5 \%)$ lives in the southern territory. $58(22.1 \%)$ income was < $500 \mathrm{JD} /$ month, 155 (58.9\%) was between 500-1000 JD/month, and 50 (19\%) was >1000 JD/month. 265 (97.3\%) had access to the internet. $136(51.7 \%)$ had previous experience in blended learning classes. $143(54.4 \%)$ had a good level of basic computer skills, 88 (33.5\%) were very good, and $32(12.2 \%)$ were excellent.

To fulfil the first and second objective of the study, we need to present the results across the sample (rather than each independent variable), so we can retain confidentiality and anonymity, and because these objectives are intended to be a test of construct validity and internal reliability of the scale. 


\section{Construct Validity}

\section{Confirmatory Factor Analysis (CFA)}

We used the structural equations to complete the CFA validation of the BLOCC scale, we needed to check how closely the collected data from the 27 specific items fitted the four-factor model proposed. Using the maximum likelihood method, we ran the CFA from the factor structure obtained previously in the exploratory analysis (Bayyat et al., 2020). The CFA analysis was only conducted for available full data questionnaires $(n=263)$.

To examine whether the proposed model fits the observed covariation matrix between items, we employed the 'two criteria strategy'; Chi-square statistic and the Root Mean Square Error of Approximation (RMSEA) (Hu $\&$ Bentler, 1999). The results shown in Table (1) reflected a moderate Chi-square indication of the overall fit for the four-factor model to the data $(\chi 2(\mathrm{df}=2.69)=603.47, \mathrm{p}<0.001$, which was within the recommended value of $\leq 5.00$ according to Hair et al (2006), while (RMSEA) of .08 estimated the amount of error of approximation per model degree of freedom and takes sample size into account and represent the approximate fit index. According to Marsh et al., (2004), RMSEA of .08 or lower should be acceptable in most cases. Hence, both fit indices indicated that data from the sample fit the model representing the latent factor structure.

Table 1. Factor loads and fit indices for the BLOCC scale

\begin{tabular}{|c|c|c|c|c|c|c|c|c|}
\hline \multirow{3}{*}{ Factor } & \multirow{3}{*}{ Item } & Initial model & & \multicolumn{5}{|c|}{ Developed model } \\
\hline & & \multicolumn{2}{|l|}{ Standardized loadings } & \multicolumn{3}{|c|}{ Standardized loadings } & \multicolumn{2}{|c|}{ Fit indices } \\
\hline & & Loading & sig & Loading & sig & $x^{2}$ & $x 2 / d f$ & RMSEA \\
\hline \multirow{6}{*}{ SMC } & 1 & 0.67 & $<0.000$ & 0.65 & $<0.000$ & \multirow{27}{*}{603.47} & \multirow{27}{*}{2.694} & \multirow{27}{*}{.80} \\
\hline & 2 & 0.71 & $<0.000$ & 0.72 & $<0.000$ & & & \\
\hline & 3 & 0.78 & $<0.000$ & 0.81 & $<0.000$ & & & \\
\hline & 4 & 0.42 & $<0.000$ & - & - & & & \\
\hline & 5 & 0.64 & $<0.000$ & 0.63 & $<0.000$ & & & \\
\hline & 6 & 0.39 & $<0.000$ & - & - & & & \\
\hline \multirow{10}{*}{ TLCC } & 7 & 0.57 & $<0.000$ & 0.56 & $<0.000$ & & & \\
\hline & 8 & 0.64 & $<0.000$ & 0.63 & $<0.000$ & & & \\
\hline & 9 & 0.67 & $<0.000$ & 0.68 & $<0.000$ & & & \\
\hline & 10 & 0.76 & $<0.000$ & 0.76 & $<0.000$ & & & \\
\hline & 11 & 0.70 & $<0.000$ & 0.66 & $<0.000$ & & & \\
\hline & 12 & 0.64 & $<0.000$ & 0.59 & $<0.000$ & & & \\
\hline & 13 & 0.55 & $<0.000$ & 0.55 & $<0.000$ & & & \\
\hline & 14 & 0.62 & $<0.000$ & 0.63 & $<0.000$ & & & \\
\hline & 15 & 0.65 & $<0.000$ & 0.66 & $<0.000$ & & & \\
\hline & 16 & 0.67 & $<0.000$ & 0.67 & $<0.000$ & & & \\
\hline \multirow{3}{*}{ SIC } & 17 & 0.68 & $<0.000$ & 0.69 & $<0.000$ & & & \\
\hline & 18 & 0.58 & $<0.000$ & 0.58 & $<0.000$ & & & \\
\hline & 19 & 0.60 & $<0.000$ & 0.60 & $<0.000$ & & & \\
\hline \multirow{8}{*}{ TCSC } & 20 & 0.71 & $<0.000$ & 0.71 & $<0.000$ & & & \\
\hline & 21 & 0.53 & $<0.000$ & 0.54 & $<0.000$ & & & \\
\hline & 22 & 0.65 & $<0.000$ & 0.61 & $<0.000$ & & & \\
\hline & 23 & 0.48 & $<0.000$ & - & - & & & \\
\hline & 24 & 0.71 & $<0.000$ & 0.72 & $<0.000$ & & & \\
\hline & 25 & 0.78 & $<0.000$ & 0.77 & $<0.000$ & & & \\
\hline & 26 & 0.71 & $<0.000$ & 0.71 & $<0.000$ & & & \\
\hline & 27 & 0.41 & $<0.000$ & - & - & & & \\
\hline
\end{tabular}


The standardized factor loadings of the initial model, shown in Table (2), revealed that all items on the scale have loaded significantly as proposed and were accepted, except items number 4,6,23, and 27 which loaded $<.05$.

As a result the BLOCC scale was modified and consisted as follows;

SMC involves a set of four challenges reflected through items 1,2,3 and 5 .

TLCC involves a set of nine challenges reflected through items 7,8,9,10,11,12,13,14 and 15.

SIC involves a set of four challenges reflected through items 16,17,18, and 19.

TSCC involves a set of six challenges reflected through items 20, 21,22,24,25, and 26.

No evidence of skewness or kurtosis revealed, which means that the distribution was roughly symmetrical and not too flat or too peaked. Table (2) reflects results according to each item, while Table (3) Appendix (1) reflects scale results according to subscales.

Table 2. Descriptive statistics for the BLOCC scale items

\begin{tabular}{|c|c|c|c|c|c|c|}
\hline Subscales & & Items & Mean & $S D$ & Skewness & Kurtosis \\
\hline \multirow{4}{*}{$S M C$} & 1 & I usually procrastinate doing my homework & 2.73 & 1.12 & 0.34 & -0.56 \\
\hline & 2 & It is hard to get help online & 2.71 & 1.25 & 0.14 & -1.00 \\
\hline & 3 & $\begin{array}{c}\text { I lack the skill of organizing/prioritizing my chores } \\
\text { and homework }\end{array}$ & 2.44 & 1.17 & 0.49 & -0.65 \\
\hline & 5 & I do not have self-managerial skills & 2.27 & 1.13 & 0.62 & -0.36 \\
\hline \multirow{9}{*}{$T L C C$} & 7 & It is hard to use the Moodle & 2.50 & 1.14 & 0.41 & -0.50 \\
\hline & 8 & I prefer not to use technology & 1.98 & 1.10 & 1.04 & 0.38 \\
\hline & 9 & I feel distracted when using technology in learning & 2.35 & 1.18 & 0.50 & -0.70 \\
\hline & 10 & I find it hard to catch up with online schooling & 2.19 & 1.00 & 0.47 & -0.52 \\
\hline & 11 & I am not good with using technology & 2.01 & 1.05 & 0.71 & -0.66 \\
\hline & 12 & I do not know much about technology & 1.60 & 0.95 & 1.45 & 1.25 \\
\hline & 13 & I feel intimidated to use technology due to my age & 1.48 & 0.83 & 1.66 & 1.80 \\
\hline & 14 & $\begin{array}{l}\text { I do not understand the need to use blended } \\
\text { learning }\end{array}$ & 2.35 & 1.22 & 0.68 & -0.47 \\
\hline & 15 & $\begin{array}{l}\text { I am against using technology as a way to get my } \\
\text { work done }\end{array}$ & 2.05 & 1.12 & 0.92 & 0.18 \\
\hline \multirow{4}{*}{$S I C$} & 16 & I feel lonely when using blended learning & 2.12 & 1.17 & 0.64 & -0.68 \\
\hline & 17 & $\begin{array}{c}\text { The feeling of isolation decreases my interest in } \\
\text { learning }\end{array}$ & 2.03 & 1.16 & 0.82 & -0.47 \\
\hline & 18 & $\begin{array}{l}\text { I face technical problems in setting up my devices } \\
\text { for online learning }\end{array}$ & 2.33 & 1.19 & 0.48 & -0.73 \\
\hline & 19 & $\begin{array}{l}\text { I feel anxious when I am the center of attention in } \\
\text { online discussion }\end{array}$ & 2.27 & 1.21 & 0.77 & -0.32 \\
\hline \multirow{6}{*}{ TSCC } & 20 & It is hard to get access to technology & 2.11 & 1.06 & 0.59 & -0.56 \\
\hline & 21 & $\begin{array}{l}\text { I do not feel that everyone is equal when it comes } \\
\text { to access to technology }\end{array}$ & 2.94 & 1.14 & -0.06 & -0.74 \\
\hline & 22 & $\begin{array}{c}\text { I notice the lack of internet and updated computer } \\
\text { devices }\end{array}$ & 2.41 & 1.16 & 0.52 & -0.49 \\
\hline & 24 & $\begin{array}{l}\text { I face technical difficulties when doing my } \\
\text { homework electronically }\end{array}$ & 2.41 & 1.09 & 0.50 & -0.31 \\
\hline & 25 & $\begin{array}{l}\text { I feel distracted by the complexity of technology } \\
\text { when doing blended learning homework }\end{array}$ & 2.38 & 1.11 & 0.52 & -0.29 \\
\hline & 26 & I find technology to be complicated & 2.12 & 0.98 & 0.44 & -0.66 \\
\hline
\end{tabular}


Table 3. Descriptive statistics for BLOCC scale subscales

\begin{tabular}{ccccccc}
\hline Subscales & Total score & Mean & Sd & RI (\%) & Skewness & Kurtosis \\
\hline SMC & 20 & 10.15 & 3.67 & 50.75 & 0.39 & -0.29 \\
TLCC & 45 & 18.51 & 6.65 & 41.13 & 0.77 & 0.18 \\
SIC & 20 & 8.75 & 3.48 & 43.75 & 0.64 & 0.20 \\
TSCC & 30 & 14.37 & 4.84 & 47.90 & 0.25 & -0.43 \\
\hline
\end{tabular}

\section{Reliability}

We checked for Item-Total Correlation, internal consistency, and composite reliability.

\section{Item-Total Correlation}

Item-Total-Correlation was conducted to examine whether scale items measure the assigned aspects of the scale. The results revealed that each item was correlated with the summated challenges of the scale, values were acceptable and ranged between .55 and .72 , see Table (4).

Table 4. Item- Total Correlation for the BLOCC scale

\begin{tabular}{|c|c|c|}
\hline Subscales & Items & $\begin{array}{l}\text { Item- total } \\
\text { correlation }\end{array}$ \\
\hline \multirow{4}{*}{ SMC } & 1 & .78 \\
\hline & 2 & .77 \\
\hline & 3 & .85 \\
\hline & 5 & .73 \\
\hline \multirow{9}{*}{ TLCC } & 7 & .63 \\
\hline & 8 & .71 \\
\hline & 9 & .70 \\
\hline & 10 & .77 \\
\hline & 11 & .74 \\
\hline & 12 & .70 \\
\hline & 13 & .60 \\
\hline & 15 & .67 \\
\hline & 16 & .71 \\
\hline \multirow{4}{*}{ SIC } & 17 & .77 \\
\hline & 18 & .79 \\
\hline & 19 & .69 \\
\hline & 20 & .70 \\
\hline \multirow{4}{*}{ TSCC } & 21 & .76 \\
\hline & 22 & .67 \\
\hline & 25 & .76 \\
\hline & 26 & .79 \\
\hline
\end{tabular}

\section{Internal Reliability}

To check the internal consistency of the items within each factor. Cronbach alpha of each factor and the total score was calculated. All subscales were internally reliable with an alpha coefficient ranging between .73 and .86, which are considered high according to Taber, (2018), see Table (5). 


\section{Composite Reliability}

To prove that items of each factor are related, we calculated the composite reliability based on the coefficients of each item. Results revealed coefficient values were greater than 0.74 . which indicated high level of composite reliability, see Table (5).

Table 5. Cronbach alpha and composite reliability (CR) of the BLOCC scale

\begin{tabular}{ccc}
\hline Subscale & Cronbach alpha & Composite reliability \\
\hline SMC & 0.79 & 0.83 \\
TLCC & 0.86 & 0.95 \\
SIC & 0.73 & 0.74 \\
TSCC & 0.83 & 0.90 \\
\hline
\end{tabular}

\section{Discriminant Validity}

To evaluate the discriminant validity of the scale, we comparef the correlations between the four subscales. Each factor should reflect a different component of online challenges, subscales that should not be related will not be, or correlate with a minimum degree. We used Fornel and Larcker criterion to assess discriminant validity, we compared the square root of each AVE in the diagonal with the correlation coefficients (offdiagonal) for each subscale in the relevant rows and columns, Table (6) supports the discriminant validity between the subscales of the BLOCC scale.

Table 6. Discriminant validity between the BLOCC subscales

\begin{tabular}{lllll}
\hline Subscale & SMC & TLCC & SIC & TSCC \\
\hline SMC & $.71^{*}$ & & & \\
TLCC & .66 & $.71^{*}$ & & \\
SIC & .53 & .56 & $.64^{*}$ & \\
TSCC & .57 & .70 & .62 & $.68^{*}$ \\
\hline
\end{tabular}

Square root of the Average Variance Extracted (AVE) (in bold, diagonal), Correlations coefficient between constructs (off-diagonal).

To fulfil the third objective of this study regarding blended learners' online component challenges (dependent variables) according to different socio-demographic variables (independent variables), descriptive data, t-tests and One-way analysis of variance (ANOVA) were provided.

Descriptive statistics for the BLOCC scale items and subscales are shown in Table (2) and Table (3) included $\mathrm{M}, \mathrm{SD}$, and relative importance index (RI). The RI percentages indicated that SMC (50.75\%) was the greatest challenge, followed by the TSCC (47.90), then SIC $(43.75 \%)$ while the least challenge was the $\operatorname{TLCC}(41.13 \%)$.

An independent-sample t-test was conducted to study the difference according to (1) gender, (2) internet accessibility, (3) previous experience in BL courses, (4) job status, (5) marital status, (6) student's nationality (7) province. While (ANOVA) was conducted to compare the effectiveness of (8) age, (9) total income per month, (10) literacy in computer skills, (11) academic year, results were presented as follows;

\section{Gender}

By comparing blended learning online component challenges between male and female participants, results revealed significant difference. On the BLOCC scale, male students were found to report higher levels of SMC $(\mathrm{t}(262)=2.81, \mathrm{p}=.005)$, TLCC $(\mathrm{t}(262)=4.04, \mathrm{p}=.00), \operatorname{SIC}(\mathrm{t}(262)=2.64, \mathrm{p}=.009)$, and TSCC $(\mathrm{t}$ $(262)=2.59, \mathrm{p}=.01)$ compared to their female peers, see Table (7). 
Table 7. Means, Standard Deviation and t test analysis for the BLOCC subscales according to gender

\begin{tabular}{|c|c|c|c|c|c|c|}
\hline \multirow[t]{2}{*}{ Subscales } & \multicolumn{2}{|c|}{$\begin{array}{c}\text { Males } \\
(n=131)\end{array}$} & \multicolumn{2}{|c|}{$\begin{array}{l}\text { Females } \\
(n=132)\end{array}$} & \multirow[t]{2}{*}{$\mathrm{t}$} & \multirow[t]{2}{*}{ sig } \\
\hline & $M$ & SD & $M$ & SD & & \\
\hline SMC & 10.78 & 3.61 & 9.52 & 3.63 & 2.81 & 0.005 \\
\hline TLCC & 20.12 & 6.97 & 16.90 & 5.92 & 4.04 & 0.000 \\
\hline SIC & 9.31 & 3.44 & 8.19 & 3.44 & 2.64 & 0.009 \\
\hline TSCC & 15.14 & 4.89 & 13.61 & 4.69 & 2.59 & 0.010 \\
\hline
\end{tabular}

Note. ${ }^{*} p<.05$

\section{Internet Accessibility}

By comparing blended learning online component challenges according to internet accessibility, results revealed significant difference. On the BLOCC scale, students with no internet accessibility were found to report higher levels of SMC ( $\mathrm{t}(262)=2.42 . \mathrm{p}=.016)$, TLCC $(\mathrm{t}(262)=2.76, \mathrm{p}=.006), \operatorname{SIC}(\mathrm{t}(262)=1.96$, $\mathrm{p}=.05)$, and TSCC $(\mathrm{t}(262)=2.1, \mathrm{p}=.036)$ compared to their peers who have internet access, see Table (8).

Table 8. Means, Standard Deviation and t test analysis for the BLOCC subscales according to internet accessibility

\begin{tabular}{|c|c|c|c|c|c|c|}
\hline \multirow[t]{2}{*}{ Subscales } & \multicolumn{2}{|c|}{$\begin{array}{c}\text { No } \\
(n=7)\end{array}$} & \multicolumn{2}{|c|}{$\begin{array}{c}\text { Yes } \\
(n=256)\end{array}$} & \multirow[t]{2}{*}{$t$} & \multirow[t]{2}{*}{ sig } \\
\hline & $M$ & SD & $M$ & SD & & \\
\hline SMC & 13.43 & 3.05 & 10.06 & 3.65 & 2.42 & 0.016 \\
\hline TLCC & 25.29 & 6.99 & 18.32 & 6.55 & 2.76 & 0.006 \\
\hline SIC & 11.29 & 2.21 & 8.68 & 3.49 & 1.96 & 0.050 \\
\hline TSCC & 18.14 & 2.04 & 14.27 & 4.86 & 2.10 & 0.036 \\
\hline
\end{tabular}

Note. ${ }^{*} p<.05$

\section{Previous Experience in BL Courses}

By comparing blended learning online component challenges according to previous experience in blended learning courses, results revealed significant difference. On the BLOCC scale, students with no internet accessibility were found to report higher levels of SMC ( $t(262)=3.87 . p=.000)$, TLCC $(\mathrm{t}(262)=4.66, \mathrm{p}=$ $.000)$, SIC $(\mathrm{t}(262)=2.46, \mathrm{p}=.014)$, and TSCC $(\mathrm{t}(262)=3.22, \mathrm{p}=.001)$ compared to their peers who have no previous experience in blended learning courses, see Table (9).

Table 9. Means, Standard Deviation and t test results for the BLOCC subscales according to previous experience in BL courses

\begin{tabular}{cccccccc}
\hline \multirow{2}{*}{ Subscales } & \multicolumn{2}{c}{$\begin{array}{c}\text { No } \\
(\mathrm{n}=127)\end{array}$} & \multicolumn{2}{c}{$\begin{array}{c}\text { Yes } \\
(\mathrm{n}=136)\end{array}$} & & $\mathrm{t}$ & sig \\
\cline { 2 - 6 } & $\mathrm{M}$ & SD & $\mathrm{M}$ & $\mathrm{SD}$ & & \\
\hline SMC & 11.03 & 3.50 & 9.32 & 3.64 & 3.87 & 0.000 \\
TLCC & 20.41 & 6.79 & 16.73 & 6.02 & 4.66 & 0.000 \\
SIC & 9.29 & 3.36 & 8.24 & 3.53 & 2.46 & 0.014 \\
TSCC & 15.35 & 4.94 & 13.46 & 4.58 & 3.22 & 0.001 \\
\hline
\end{tabular}

Note. ${ }^{*} p<.05$ 
Nevertheless, results revealed no significance differences for the blended learning online component challenges according to their job status, marital status, province, see Table (10-12).

Table 10. Means, Standard Deviation and t test results for the BLOCC subscales according to job status

\begin{tabular}{|c|c|c|c|c|c|c|}
\hline \multirow[t]{2}{*}{ Subscales } & \multicolumn{2}{|c|}{$\begin{array}{l}\text { Have a job } \\
\qquad(n=92)\end{array}$} & \multicolumn{2}{|c|}{$\begin{array}{l}\text { Do not have a job } \\
\qquad(n=171)\end{array}$} & \multirow[t]{2}{*}{$\mathrm{T}$} & \multirow[t]{2}{*}{ sig } \\
\hline & M & SD & M & SD & & \\
\hline SMC & 10.20 & 3.76 & 10.12 & 3.63 & 0.15 & 0.787 \\
\hline TLCC & 19.01 & 6.94 & 18.23 & 6.49 & 0.90 & 0.367 \\
\hline SIC & 8.60 & 3.61 & 8.83 & 3.41 & 0.51 & 0.606 \\
\hline TSCC & 14.57 & 4.72 & 14.26 & 4.92 & 0.48 & 0.630 \\
\hline
\end{tabular}

Note. ${ }^{*} p<.05$

Table 11. Means, Standard Deviation and t test results for the BLOCC subscales according to marital status

\begin{tabular}{|c|c|c|c|c|c|c|}
\hline \multirow[t]{2}{*}{ Subscales } & \multicolumn{2}{|c|}{$\begin{array}{l}\text { Single } \\
(n=251)\end{array}$} & \multicolumn{2}{|c|}{$\begin{array}{c}\text { Married } \\
(n=12)\end{array}$} & \multirow[t]{2}{*}{$\mathrm{t}$} & \multirow[t]{2}{*}{ sig } \\
\hline & $M$ & SD & $M$ & SD & & \\
\hline SMC & 10.19 & 3.74 & 9.33 & 1.30 & 0.78 & 0.432 \\
\hline TLCC & 18.47 & 6.73 & 19.17 & 4.73 & 0.35 & 0.725 \\
\hline SIC & 8.72 & 3.53 & 9.42 & 2.15 & 0.68 & 0.497 \\
\hline TSCC & 14.23 & 4.89 & 17.33 & 2.19 & 2.18 & 0.300 \\
\hline
\end{tabular}

Note. ${ }^{*} p<.05$

Table 12. Means, Standard Deviation and t test results for the BLOCC subscales according to province

\begin{tabular}{|c|c|c|c|c|c|c|}
\hline \multirow[t]{2}{*}{ Subscales } & \multicolumn{2}{|c|}{$\begin{array}{l}\text { Central territory } \\
\qquad(n=231)\end{array}$} & \multicolumn{2}{|c|}{$\begin{array}{l}\text { North territory } \\
\qquad(n=28)\end{array}$} & \multirow[t]{2}{*}{$\mathrm{t}$} & \multirow[t]{2}{*}{ sig } \\
\hline & $M$ & SD & $M$ & SD & & \\
\hline SMC & 10.04 & 3.61 & 10.96 & 4.10 & 1.26 & 0.208 \\
\hline TLCC & 18.31 & 6.63 & 19.46 & 7.05 & 0.86 & 0.389 \\
\hline SIC & 8.70 & 3.37 & 8.54 & 3.86 & 0.24 & 0.809 \\
\hline TSCC & 14.30 & 4.74 & 13.82 & 4.94 & 0.50 & 0.614 \\
\hline
\end{tabular}

Note. ${ }^{*} p<.05$

The south territory was excluded $(n=4)$

Age

Results related to age groups revealed significant difference in TLCC and TSCC; $F(2,260)=5.74, p=0.004$ and $F(2,260)=3.28, p=0.039$ respectively. Post hoc analyses using the Scheffé post hoc criterion for significance indicated that; TLCC was significantly higher in the age group 26-30 $(\mathrm{M}=22.29, \mathrm{SD}=4.61)$ than in the other two age groups $(<20$ and $21-25)(\mathrm{M}=19.05, \mathrm{SD}=6.91),(\mathrm{M}=16.81, \mathrm{SD}=5.99)$ respectively, $\mathrm{F}(2,260)=5.74, \mathrm{p}=0.004$, and finally TSCC was significantly higher in the age group 26-30 $(\mathrm{M}=17.36, \mathrm{SD}=3.05)$ than in the other two age groups $(<20$ and $21-25)(\mathrm{M}=14.40, \mathrm{SD}=5.05),(\mathrm{M}=$ $13.81, \mathrm{SD}=13.81)$ respectively, $\mathrm{F}(2,260)=3.28, \mathrm{p}=.039$, see Table $(13 \mathrm{a}-\mathrm{b})$. 
Table 13a. Means, Standard Deviation and One-way ANOVA for the BLOCC subscales according to age

\begin{tabular}{|c|c|c|c|c|c|c|c|c|c|}
\hline \multirow[t]{2}{*}{ Subscales } & \multicolumn{2}{|c|}{$\begin{array}{c}<20 \\
(n=165)\end{array}$} & \multicolumn{2}{|c|}{$\begin{array}{l}21-25 \\
(n=84)\end{array}$} & \multicolumn{2}{|c|}{$\begin{array}{l}26-30 \\
(n=14)\end{array}$} & \multirow[t]{2}{*}{$F(2,263)$} & \multirow[t]{2}{*}{ sig } & \multirow[t]{2}{*}{$\eta 2$} \\
\hline & $M$ & SD & M & SD & $M$ & SD & & & \\
\hline SMC & 10.36 & 3.76 & 9.57 & 3.33 & 11.07 & 4.25 & 1.77 & 0.171 & 0.013 \\
\hline TLCC & 19.05 & 6.91 & 16.81 & 5.99 & 22.29 & 4.61 & 5.74 & $0.004 *$ & 0.042 \\
\hline SIC & 9.00 & 3.43 & 8.12 & 3.51 & 9.57 & 3.52 & 2.21 & 0.111 & 0.017 \\
\hline TSCC & 14.40 & 5.05 & 13.81 & 4.51 & 17.36 & 3.05 & 3.28 & $0.039 *$ & 0.025 \\
\hline
\end{tabular}

* indicate significant differences within the categories of the independent variable

Table 13b. Scheffe post hoc test for the BLOCC significant subscales according to age

\begin{tabular}{ccccc}
\hline Subscales & age & M & $21-25$ & $26-30$ \\
\hline \multirow{3}{*}{ TLCC } & $<20$ & 19.05 & 0.040 & \\
& $21-25$ & 16.81 & & \\
& $26-30$ & 22.29 & 0.016 & \\
\multirow{2}{*}{ TSCC } & $<20$ & 14.40 & & \\
& $21-25$ & 13.81 & & \\
& $26-30$ & 17.36 & 0.039 \\
\hline
\end{tabular}

\section{Total Income per Month}

Also, ANOVA results related to total income/ month reflected significant differences in TLCC and TSCC; $\mathrm{F}(2,260)=6.56, \mathrm{p}=0.002$ and $\mathrm{F}(2,260)=3.96, \mathrm{p}=0.020$ respectively. Post hoc analyses using the Scheffé post hoc criterion for significance indicated that; TLCC was significantly higher in the income/ month group $<500 \mathrm{JD}(\mathrm{M}=20.93, \mathrm{SD}=6.53)$ than in the other two income/ month groups ( $500-1000 \mathrm{JD}$ and $>1000 \mathrm{JD})(\mathrm{M}=19.05, \mathrm{SD}=6.91),(\mathrm{M}=18.25, \mathrm{SD}=6.99)$ respectively, $\mathrm{F}(2,260)=6.56, \mathrm{p}=0.002$, and finally TSCC was significantly higher in the income/ month group $<500 \mathrm{JD}(\mathrm{M}=15.83, \mathrm{SD}=4.19)$ than in the other two groups (500-1000 JD and $>1000 \mathrm{JD})(\mathrm{M}=14.15, \mathrm{SD}=5.00),(\mathrm{M}=13.36, \mathrm{SD}=4.75)$ respectively, $\mathrm{F}(2,260)=3.96, \mathrm{p}=0.020$, see Table $(14 \mathrm{a}-\mathrm{b})$.

Table 14a. Means, Standard Deviation and One-way ANOVA for the BLOCC subscales according to total income per month

\begin{tabular}{|c|c|c|c|c|c|c|c|c|c|}
\hline \multirow[t]{2}{*}{ Subscales } & \multicolumn{2}{|c|}{$\begin{array}{c}<500 \mathrm{JD} \\
(\mathrm{n}=58)\end{array}$} & \multicolumn{2}{|c|}{$\begin{array}{c}500-1000 \mathrm{JD} \\
(\mathrm{n}=155)\end{array}$} & \multicolumn{2}{|c|}{$\begin{array}{c}>1000 \mathrm{JD} \\
(\mathrm{n}=50)\end{array}$} & \multirow[t]{2}{*}{$F(2,263)$} & \multirow[t]{2}{*}{ sig } & \multirow[t]{2}{*}{$\eta 2$} \\
\hline & $M$ & SD & $M$ & SD & M & SD & & & \\
\hline SMC & 11.07 & 3.72 & 10.05 & 3.47 & 9.40 & 4.05 & 2.97 & 0.053 & 0.022 \\
\hline TLCC & 20.93 & 6.53 & 18.25 & 6.99 & 16.48 & 4.65 & 6.56 & 0.002 & 0.048 \\
\hline SIC & 9.36 & 3.36 & 8.52 & 3.58 & 8.76 & 3.29 & 1.24 & 0.288 & 0.010 \\
\hline TSCC & 15.83 & 4.19 & 14.15 & 5.00 & 13.36 & 4.75 & 3.96 & 0.020 & 0.030 \\
\hline
\end{tabular}


Table 14b. Scheffe post hoc test for the BLOCC significant subscales according to total income per month

\begin{tabular}{ccccc}
\hline Subscales & Income level & $M$ & $500-1000$ & $>1000 \mathrm{jd}$ \\
\hline \multirow{2}{*}{ TLCC } & $<500 \mathrm{jd}$ & 20.93 & 0.029 & 0.002 \\
& $500-1000$ & 18.25 & & 0.030 \\
\hline & $>1000 \mathrm{jd}$ & 16.48 & \\
\hline \multirow{2}{*}{ TSCC } & $<500 \mathrm{jd}$ & 15.83 & \\
& $500-1000$ & 14.15 & \\
\hline
\end{tabular}

\section{Literacy in Computer Skills}

Accordingly, ANOVA results related to literacy in computer skills level reflected significant differences in SMC, TLCC, and TSCC; $F(2,260)=10.79, \mathrm{p}=0.000, \mathrm{~F}(2,260)=22.80, \mathrm{p}=0.000$, and $\mathrm{F}(2,260)=12.03$, $\mathrm{p}=0.000$ respectively. Post hoc analyses using the Scheffé post hoc criterion for significance indicated that; SMC was significantly higher in the Computer literacy group Fair computer literacy $(\mathrm{M}=11.04, \mathrm{SD}=3.45)$ than in the other two Computer literacy groups (Good and Excellent) $(\mathrm{M}=9.33, \mathrm{SD}=3.71),(\mathrm{M}=8 . .41$, $\mathrm{SD}=3.44)$ respectively $\mathrm{F}(2,260)=10.79, \mathrm{p}=0.000$. TLCC was significantly higher in the Computer literacy group Fair computer literacy $(\mathrm{M}=20.82, \mathrm{SD}=6.75)$ than in the other two Computer literacy groups (Good and Excellent $)(M=16.15, S D=5.63),(M=14.66, S D=4.49)$ respectively $F(2,260)=22.80, p=0.000$, and finally TSCC was significantly higher in the Computer literacy group Fair $(\mathrm{M}=15.65, \mathrm{SD}=4.75)$ than in the other two groups (Good and Excellent) $(\mathrm{M}=12.98, \mathrm{SD}=4.19),(\mathrm{M}=12.47, \mathrm{SD}=5.38)$ respectively, $\mathrm{F}(2,260)=12.03, \mathrm{p}=0.000$, see Table $(15 \mathrm{a}-\mathrm{b})$.

Table 15a. Means, Standard Deviation and One-way ANOVA for the BLOCC subscales according to literacy in computer skills level

\begin{tabular}{|c|c|c|c|c|c|c|c|c|c|}
\hline \multirow[t]{2}{*}{ Subscales } & \multicolumn{2}{|c|}{$\begin{array}{c}\text { Fair } \\
(n=143)\end{array}$} & \multicolumn{2}{|c|}{$\begin{array}{c}\text { Good } \\
(n=88)\end{array}$} & \multicolumn{2}{|c|}{$\begin{array}{c}\text { Excellent } \\
(\mathrm{n}=32)\end{array}$} & \multirow[t]{2}{*}{$F(2,263)$} & \multirow[t]{2}{*}{ sig } & \multirow[t]{2}{*}{$\eta 2$} \\
\hline & $M$ & SD & $M$ & SD & $M$ & SD & & & \\
\hline SMC & 11.04 & 3.45 & 9.33 & 3.71 & 8.41 & 3.44 & 10.79 & 0.000 & 0.077 \\
\hline TLCC & 20.82 & 6.75 & 16.15 & 5.63 & 14.66 & 4.49 & 22.80 & 0.000 & 0.149 \\
\hline SIC & 9.01 & 3.43 & 8.33 & 3.47 & 8.75 & 3.73 & 1.03 & 0.358 & 0.008 \\
\hline TSCC & 15.65 & 4.75 & 12.98 & 4.19 & 12.47 & 5.38 & 12.03 & 0.000 & 0.085 \\
\hline
\end{tabular}

Table 15b. Scheffe post hoc test for the BLOCC significant subscales according to literacy in computer skills level

\begin{tabular}{ccccc}
\hline Subscales & Computer skills level & M & Good & Excellent \\
\hline \multirow{2}{*}{ SMC } & Fair & 11.04 & 0.002 & 0.001 \\
& Good & 9.33 & & \\
\hline \multirow{2}{*}{ TLCC } & Excellent & 8.41 & & 0.000 \\
& Fair & 20.82 & 0.000 & \\
& Good & 16.15 & & 0.003 \\
& Excellent & 14.66 & & 0.000 \\
\end{tabular}


No significant differences revealed according to academic year in all subscale components SMC, TLCC, SIC and TSCC as follows; $\mathrm{F}(3,259)=0.19, \mathrm{p}=0.897, \mathrm{~F}(3,259)=1.65, \mathrm{p}=0.178, \mathrm{~F}(3,259)=778, \mathrm{p}=0.502$, and $\mathrm{F}(3,259)=43, \mathrm{p}=0.728$, see Table $(16)$.

Table 16. Means, Standard Deviation and One-way ANOVA for the BLOCC subscales according to academic year

\begin{tabular}{|c|c|c|c|c|c|c|c|c|c|c|c|}
\hline \multirow[t]{2}{*}{ Subscales } & \multicolumn{2}{|c|}{$\begin{array}{c}\text { First } \\
(n=133)\end{array}$} & \multicolumn{2}{|c|}{$\begin{array}{l}\text { Second } \\
(n=69)\end{array}$} & \multicolumn{2}{|c|}{$\begin{array}{l}\text { Third } \\
(n=21)\end{array}$} & \multicolumn{2}{|c|}{$\begin{array}{l}\text { Fourth } \\
(n=40)\end{array}$} & \multirow[t]{2}{*}{$\begin{array}{c}F \\
(3,262)\end{array}$} & \multirow[t]{2}{*}{ sig } & \multirow[t]{2}{*}{$\eta 2$} \\
\hline & $M$ & SD & $M$ & SD & $M$ & SD & $M$ & SD & & & \\
\hline SMC & 10.26 & 3.56 & 9.99 & 4.13 & 10.48 & 4.00 & 9.90 & 3.08 & 0.19 & 0.897 & 0.002 \\
\hline TLCC & 19.19 & 6.89 & 18.10 & 6.82 & 19.05 & 6.47 & 16.65 & 5.31 & 1.65 & 0.178 & 0.019 \\
\hline SIC & 8.76 & 3.53 & 8.75 & 3.49 & 9.67 & 4.08 & 8.23 & 2.97 & 0.778 & 0.502 & 0.009 \\
\hline TSCC & 14.28 & 4.90 & 14.58 & 5.15 & 15.24 & 4.96 & 13.85 & 4.07 & 0.43 & 0.728 & 0.005 \\
\hline
\end{tabular}

\section{DISCUSSIONS}

Although the blended learning approach is popular, highly adopted, and beneficial in optimizing teaching and learning (Dziuban et al., 2018), the inclusion of technology creates online component level of unease to students. Students' self-management skills and technological competences are crucial to effectively manage and carry out their educational responsibilities independently of their instructors, and implementing online technology (Rasheed et al, 2020)

This study has focused on the online component of blended learning rather than addressing the design challenges as a whole, we validated and implemented the BLOCC scale, the results were in accordance with several studies which have reported challenges that students face in the online component of blended learning.

Based on our results, the validaty and reliability of the BLOCC scale were confirmed, the final version of the scale consisted of 23 items, distributed into the four proposed subscales; self-management challenges (SMS), technological literacy and competency challenges (TLCC), students' isolation challenges (SIC), and technological sufficiency and complexity challenges (TSCC). For further validation, we also checked the ability of the scale to identify differences between the sample of the study according to various sodio-demographic variables.

Hence, we will discuss the results of our study regarding the challenges and differences according to the previously mentioned four BLOCC subscales;

First, 'self-management challenges' (SMC; $n=4$ ) which involve behaviors that deter students from selfmanaging their thoughts, feelings and actions to achieve their learning goals.

Results of the study revealed that male students, students who have no internet accessibility, those who have no previous experience in blended learning classes, and students with lower literacy in computer skills level have encountered significant levels in SMC. This might be attributed to the fact that Blended learning offers students the freedom of learning at one's pace, flexibility and autonomy to organize and self-manage their learning activities. According to Chuang et al., (2018), Lightner \& Lightner-Laws, (2016), Cakiroglu \& Ozturk, (2017) students exibit 'self-regulation' as a challenge, they have poor self-management skills to organize and manage their learning tasks independently, and they relatively spend small portion of their time in learning tasks. Basically, they find it difficult to organize and prioritize their chores and homework, they feel they lack managerial skills.

Procrastination is also one form of self-management, students procrastinate doing their homework (Broadbent, 2017; Sun, Wu, \& Lee, 2017; AlJarrah et al., 2018; Maycock et al., 2018). It is considered a psychological dysfunction and a harmful behavior present in online learning settings, where students experience a larger sense of transactional distance (Boelens et al., 2017; Van Eerde \& Klingsieck, 2018). Davis \& Abbitt, (2013) claimed that the use of mobile application (Moodle application) for smartphones reduced their procrastination level, and that mobile application is used as an intervention tool that alerts and stimuli students to illuminate procrastination. 
Students tend to interact and connect with their colleagues through the online platform and through forums discussions (Rasheed et al., 2020). Yet, Chen et al., (2015), Broadbent, (2017), and Akcayir \& Akcayir, (2018) reported that students encountered difficulties connecting with their peers and getting appropriate online help. Safford \& Stinton, (2016) stated that students feel intimidated by seeking online help, which might lead to searching unreliable sources (Broadbent, 2017).

Secondly, 'technological literacy and competency challenges' (TLCC; $n=9$ ) which involve students' proficiency and competency that effect their use of technology for studying. Results of this study revealed that male students, students who have no internet accessibility, those who have no previous experience in blended learning classes, older students (26-30 years old), those with the lowest total income/ month $(<$ $500 \mathrm{JD}$ ) and students with lower literacy in computer skills level encountered significant levels in TLCC. Although computer skills are essential for blended learning process, the sample of this study declared that they did not know much about technology and were not good with at it. and prefered not to. They felt distract when using technology in learning and did not know how to use the platform "Moodle", in addition to dealing with different technological user interfaces (Prasad et al., 2018). They found it hard to catch up with online classes, some students did not understand the need to use blended learning, and felt intimidated to use technology due to their age. Akcayir \& Akcayir, (2018), on the other hand, argued that students of this generation are assumed to have less difficulties in using technology than the former generations, some were even against the use of technology to get my work done. These results are in accordance with Zacharis (2015) who emphasized the effect of students' technological illiteracy on the delay of interacting with their instructors and peers, leading to definite procrastination and setbacks in their performance. Thus, it is important to emphasize the fact that both technology literacy and competency are crucial for blended learning students.

Thirdly, 'students isolation challenges' (SIC; $\mathrm{n}=4$ ), involve students' suffering from emotional discomfort due to seclusion and loneliness (Lightner \& Lightner- Laws, 2016; Chyr et al., 2017). Results of this study revealed that Male students, students who have no internet accessibility, and those who have no previous experience in blended learning classes encountered significant levels in SIC. Students felt lonely when using blended learning, their feeling of isolation decreased their interest and motivation for learning, according to Rasheed (2020) this might result in challenges in activities of preparations and assignments. Students felt anxious when they were the center of attention during online discussions, whether the reason was video conferences or using the microphones (Bower, 2015; Szeto \& Cheng, 2016). They also had technical problems in setting up their devices for online learning.

Fourthly, 'Technological sufficiency and complexity challenges' (TSCC; $n=4$ ) involve facing sufficient or complex online technologies and services challenges for their studies. Results of this study revealed that male students, students who have no internet accessibility, those who have no previous experience in blended learning classes, and Students with lower literacy in computer skills level encountered significant levels in TSCC. Students felt that it was hard for them to get access to technology, and not everyone is equal when it comes to access to technology (Chen et al., 2015; Akcayir \& Akcayir, 2018). Some students lack access to internet such as; a high broadband Wi-Fi or updated computer devices (Rasheed, 2020). Also, students might have found technology to be complicated, or they might face technical difficulties when doing their homework electronically and feel distracted, their time and focus would be spend on learning how to use new technology rather than doing their homework (Safford \& Stinton, 2016; Prasad et al., 2018).

\section{CONCLUSION}

This study aims to provide the blended learning literature with detailed picture of the students' online component challenges from their own perspective. To do so, we validated the BLOCC scale, and implemented it to study the online component challenges according to different sample characteristics.

The BLOCC scale included four subscales: Self- Management Challenges (SMC), Technology Literacy and Competency Challenges (TLCC), Student Isolation Challenges (SIC), and Technological Sufficiency and Complexity Challenges (TSCC). BLOCC scale proved to be valid and reliable; The overall fit statistics for the hypothesized four factor model $\left(\chi^{2}(\mathrm{df}=2.69)=603.47, \mathrm{p}<0.001,(\mathrm{RMSEA})=.08\right.$ indicated a moderate and acceptable fit to the data representing the latent factor structure. Four items were excluded. 
Reliability was assessed; Item-to-total correlation (.55 and .72), Cronbach Alpha (.72 and .86), and composite reliability $(.74-.95)$. Also, the results of discriminant validity ranged between .53 and .70 . expressing a good discriminate validity. Thus, the BLOCC scale adapted was suitable to study the online component challenges of blended learning, mainly these four subscales. Results of the study revealed that male students, students who have no internet accessibility, and those who have no previous experience in blended learning classes, all encountered significant levels in all subscales. Older students (26-30 years old), and those with the lowest total income/ month $(<500 \mathrm{JD})$ encountered significant levels of TLCC and TSCC. Students with lower literacy in computer skills level encountered significant differences in SMC, TLCC and TSCC. While no significant differences revealed according to their job status, marital status, student nationality, province, and academic year in all subscale components. A limitation of this scale is that it was suitable to be used in the BL classes at the School of Sport Sciences/ University of Jordan. However, future studies are encouraged for a different and much bigger sample to further validate the instrument. We encourage future studies to propose and implement curative approaches to face such online component challenges, such as a repetitive training and guiding process to learners, group awareness and peer assistance and carefully structure both the face-to-face and online components ( Lin et al., 2016; Rasheed, 2020). Also, stakeholders might benefit from the results of the learners' online component challenges for future planning.

\section{BIODATA and CONTACT ADDRESSES of AUTHORS}

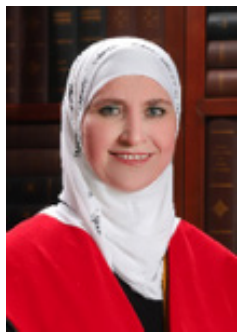

Dr. Manal BAYYAT, is an Associate Professor of Sport Psychology, Life Skills, Fencing and Ballet at the School of Sport Science, University of Jordan. Dr. Bayyat recieved her Ph.D. in Physical Education in 2009. Her academic interest areas are learning analytics, sport psychological analytics, social work, blended learning, cyber behaviors and use of internet in education. She has over than 15 journal articles published in international indexes. She participated in several national and international meetings in which her papers where submitted.

\section{Manal BAYYAT}

School of Sport Science

Address: University of Jordan, Postal Code 11942, Amman, Jordan

Phone: +962790354435

E-mail: mabayyat@yahoo.com / m.bayyat@ju.edu.jo

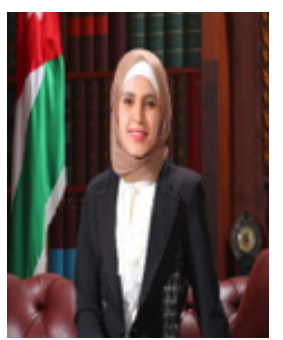

Zainab Helmy ABU MUAILI, a PhD student at the School of Sports Sciences, University of Jordan, majoring in Sports Psychology and Motor Learning, I completed my Masters degree in 2019 in Supervision and Teaching in Physical Education from the University of Jordan, and published many research papers in national and international journals.

Zainab Helmy ABU MUAILI

School of Sport Science

Address: University of Jordan, Postal Code 11942, Amman, Jordan

Phone: +962790400797

E-mail: zainab.helmy77@yahoo.com 


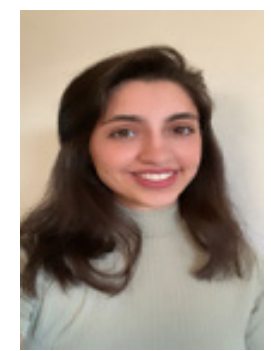

Lujayn ALDABBAS is a computer engineer who graduated from Princess Sumaya University for Technology. She was the chairwoman of IEEE student branch on campus and participated in international and national events and competitions. She is certified in CCNA Routing and switching, and CCNA Security. She also likes programming and working on projects in her free time.

Lujayn ALDABBAS

Princess Sumaya University for Technology

Phone: +491602023946

E-mail: dabbas.lujayn@gmail.com

\section{REFERENCES}

Ab Hamid, M. R., Sami, W., \& Sidek, M. M. (2017). Discriminant validity assessment: Use of Fornell \& Larcker criterion versus HTMT criterion. In Journal of Physics: Conference Series (Vol. 890, No. 1, p. 012163). IOP Publishing. https://doi.org/10.1088/1742-6596/890/1/012163

Akcayir, G., \& Akcayir, M. (2018). The flipped classroom: A review of its advantages and challenges. Computers \& Education, 126, 334-345. https://doi.org/10.1016/j.compedu.2018.07.021

AlJarrah, A., Thomas, M. K., \& Shehab, M. (2018). Investigating temporal access in a flipped classroom: Procrastination persists. International Journal of Educational Technology in Higher Education, 15(1), 1. https://doi.org/10.1186/s41239-017-0083-9

Bailey, K. D., \& Morais, D. B. (2005). Exploring the use of blended learning in tourism education. Journal of Teaching in Travel \& Tourism, 4(4), 23-36. https://doi.org/10.1300/J172v04n04_02

Bayyat, M., Al Dabbas, L., \& Abu Muili, Z. (2020). Development and Validation of the "Blended Learners' Online Component Challenges" Scale [Manuscript submitted for publication]

Boelens, R., De Wever, B., \& Voet, M. (2017). Four key challenges to the design of blended learning: A systematic literature review. Educational Research Review, 22, 1-18. https://doi.org/10.1016/j. edurev.2017.06.001

Bonk, C. J., Olson, T. M., Wisher, R. A., \& Orvis, K. L. (2002). Learning from focus groups: An examination of blended learning. International Journal of E-Learning \& Distance Education, 17(3), 97-118.

Bourne, J., Harris, D., \& Mayadas, F. (2005). Online engineering education: Learning anywhere, anytime. Journal of Engineering Education, 94, 131-146. https://doi.org/10.1002/j.2168-9830.2005. tb00834.x

Bower, M., \& Sturman, D. (2015). What are the educational affordances of wearable technologies?. Computers \& Education, 88, 343-353. https://doi.org/10.1016/j.compedu.2015.07.013

Broadbent, J. (2017). Comparing online and blended learner's self-regulated learning strategies and academic performance. The Internet and Higher Education, 33, 24-32. https://doi.org/10.1016/j. iheduc.2017.01.004

Chen, L., Chen, T. L., \& Chen, N. S. (2015). Students' perspectives of using cooperative learning in a flipped statistics classroom. Australasian Journal of Educational Technology, 31(6). https://doi. org/10.14742/ajet.1876

Chuang, H. H., Weng, C. Y., \& Chen, C. H. (2018). Which students benefit most from a flipped classroom approach to language learning?. British Journal of Educational Technology, 49(1), 56-68. https:// doi.org/10.1111/bjet.12530 
Chyr, W.-L., Shen, P.-D., Chiang, Y.-C., Lin, J.-B., \& Tsai, C.-W. (2017). Exploring the effects of online academic help-seeking and flipped learning on improving students' learning. Journal of Educational Technology \& Society, 20(3), 11-23.

Dalsgaard, C., \& Godsk, M. (2007). Transforming traditional lectures into problem-based blended learning: challenges and experiences. Open learning, 22(1), 29-42. https://doi. org/10.1080/02680510601100143

Dos, B. (2014). Developing and evaluating a blended learning course. The Anthropologist, 17(1), 121-128. https://doi.org/10.1080/09720073.2014.11891421

Dziuban, C., Graham, C. R., Moskal, P. D., Norberg, A., \& Sicilia, N. (2018). Blended learning: The new normal and emerging technologies. International Journal of Educational Technology in Higher Education, 15(1), 3. https://doi.org/10.1186/s41239-017-0087-5.

Feng, S. (2018). Applied Research on College Sports Blended Learning Based on Moodle Platform. Educational Sciences: Theory \& Practice, 18(5). https://doi.org/10.12738/estp.2018.5.010

Guzer, B., \& Caner, H. (2014). The past, present and future of blended learning: an in depth analysis of literature. Procedia-social and behavioral sciences, 116, 4596-4603. https://doi.org/10.1016/j. sbspro.2014.01.992

Hair, J. F., Black, W. C., Babin, B. J., Anderson, R. E., \& Tatham, R. L. (1998). Multivariate data analysis (Vol. 5, No. 3, pp. 207-219). Upper Saddle River, NJ: Prentice hall.

Hu, L. T., \& Bentler, P. M. (1999). Cutoff criteria for fit indices in covariance structure analysis: Sensitivity under parameterized model misspecification. Structural Equation Modeling, 6(1), 1-55.

Hughes, G. (2007). Using blended learning to increase learner support and improve retention. Teaching in Higher Education, 12(3), 349-363. https://doi.org/10.1080/13562510701278690

Keogh, J. W., Gowthorp, L., \& McLean, M. (2017). Perceptions of sport science students on the potential applications and limitations of blended learning in their education: a qualitative study. Sports biomechanics, 16(3), 297-312. https://doi.org/10.1080/14763141.2017.1305439

Le, Y. (2011). Application of computer and multimedia technology in college physical education. Circuits, Communications \& System, 1-3. http://dx.doi.org/10.1109/PACCS.2011.5990343

Lin, J. W., Lai, Y. C., Lai, Y. C., \& Chang, L. C. (2016). Fostering self-regulated learning in a blended environment using group awareness and peer assistance as external scaffolds. Journal of Computer Assisted Learning, 32(1), 77-93. https://doi.org/10.1111/jcal.12120

Lightner, C.A., \& Lightner-Laws, C.A. (2016) A blended model: simultaneously teaching a quantitative course traditionally, online, and remotely, Interactive Learning Environments, 24:1, 224-238, DOI: $10.1080 / 10494820.2013 .841262$

Marsh, H. W., Hau, K. T., \& Wen, Z. (2004). In search of golden rules: Comment on hypothesis-testing approaches to setting cutoff values for fit indexes and dangers in overgeneralizing Hu and Bentler's (1999) findings. Structural equation modeling, 11(3), 320-341. https://doi.org/10.1207/ s15328007sem1103_2

Maycock, K. W., Lambert, J., \& Bane, D. (2018). Flipping learning not just content: A 4-year action research study investigating the appropriate level of flipped learning. Journal of Computer Assisted Learning, 34(6), 661-672. https://doi.org/10.1111/jcal.12274

Mitchell, P., \& Forer, P. (2010). Blended learning: The perceptions of first-year geography students. Journal of Geography in Higher Education, 34(1), 77-89. https://doi.org/10.1080/03098260902982484

Napier, N. P., Dekhane, S., \& Smith, S. (2011). Transitioning to blended learning: Understanding student and faculty perceptions. Journal of Asynchronous Learning Networks, 15(1), https://doi.org/2032. $10.24059 /$ olj.v15i1.188 
Prasad, P. W. C., Maag, A., Redestowicz, M., \& Hoe, L. S. (2018b). Unfamiliar technology: Reaction of international students to blended learning. Computers \& Education, 122, 92-103. https://doi. org/10.1016/j.compedu.2018.03.016.

Pizzi, M. A. (2014). Blended learning pedagogy: the time is now!. Occupational therapy in health care, 28(3), 333-338. https://doi.org/10.3109/07380577.2014.908479

Rasheed, R. A., Kamsin, A., \& Abdullah, N. A. (2020). Challenges in the online component of blended learning: A systematic review. Computers \& Education, 144, 103701. https://doi.org/10.1016/j. compedu.2019.103701

Safford, K., \& Stinton, J. (2016). Barriers to blended digital distance vocational learning for non-traditional students. British Journal of Educational Technology, 47(1), 135-150. https://doi.org/10.1111/ bjet. 12222

Stubbs, M., Martin, I., \& Endlar, L. (2006). The structuration of blended learning: putting holistic design principles into practice. British Journal of Educational Technology, 37(2), 163-175. http://dx.doi. org/10.1111/j.1467-8535.2006.00530.x

Sun, J. C. Y., Wu, Y.T., \& Lee, W. I. (2017). The effect of the flipped classroom approach to OpenCourseWare instruction on students' self-regulation. British Journal of Educational Technology, 48(3), 713729. https://doi.org/10.1111/bjet.12444

Szeto, E., \& Cheng, A. Y. (2016). Towards a framework of interactions in a blended synchronous learning environment: What effects are there on students' social presence experience? Interactive Learning Environments, 24(3), 487-503. https://doi.org/10.1080/10494820.2014.881391

Tay, H. Y. (2016). Investigating engagement in a blended learning course. Cogent Education, 3(1), 1135772. https://doi.org/10.1080/2331186X.2015.1135772

Taber, K. S. (2018). The use of Cronbach's alpha when developing and reporting research instruments in science education. Research in Science Education, 48(6), 1273-1296. DOI 10.1007/s11165-016$9602-2$

Tamim, R. M. (2018). Blended Learning for Learner Empowerment: Voices from the Middle East. Journal of Research on Technology in Education, 50(1), 70-83. https://doi.org/10.1080/15391523.201 7.1405757

Van Eerde, W., \& Klingsieck, K. B. (2018). Overcoming procrastination? A meta-analysis of intervention studies. Educational Research Review, 25, 73-85. https://doi.org/10.1016/j.edurev.2018.09.002

Zacharis, N. Z. (2015). A multivariate approach to predicting student outcomes in web-enabled blended learning courses. The Internet and Higher Education, 27, 44-53. https://doi.org/10.1016/j. iheduc.2015.05.002

Zhou, Y., Zhou, Y., \& Zhou, Y. (2017). Design of moodle-based podcast teaching platform for the course of aerobic gymnastics. International Journal of Emerging Technologies in Learning, 12(9), 95-104. http://dx.doi.org/10.3991/ijet.v12i09.7490 